\title{
Design of a mechatronic unit for application of coats of adhesive
}

\author{
Aleksandra Fierek ${ }^{1,}$, Ireneusz Malujda ${ }^{1}$, and Krzysztof Talaśka ${ }^{1}$ \\ ${ }^{1}$ Chair of Basics of Machine Design, Poznan University of Technology, Poznań, Poland
}

\begin{abstract}
This paper presents the chosen structural design and confirms the need of a mechatronic system for application of adhesive on parts of seating systems for public transport vehicles. The design assumptions concerning the mechanical part of the machine and control system design are given. The engineering calculations for the chosen structural joints are described. The chosen driving systems are presented and the method for removing excess adhesive is proposed. The control system design is described is described towards the end of this paper. Information is given on the control block diagram which was used for selecting the system components. PLC, motor controllers and the associated sensors are specified. Conclusions are presented at the end of this paper.
\end{abstract}

Keywords: gluing (adhesive bonding), gluing machine, process automation

\section{Introduction}

The project including the design and construction of a mechatronic system for application of coats of adhesive was triggered off by the need to implement automation in the process of adhesive application on the parts of the seating for system public transport vehicles produced at the Kiel manufacturing site in Nowy Tomyśl, Poland. Currently manual spray guns are used which does not ensure the required level of repeatability and efficiency of the process in question. This spurred the efforts to develop a mechatronic system for spray application of adhesive coating, whose engineering details are described further below.

The engineering work proper was preceded by a state of knowledge review. The seating systems were examined to establish their construction and dimensions of their components [1]. The existing methods of application of various coatings were reviewed [2, 3]. Attention was paid also to the spray unit itself $[4,5]$. The properties of adhesive were studied. These input data served to determine the outline specifications and requirements for the designed machine, as given below:

- the machine work area is a $600 \times 800 \mathrm{~mm}$ rectangle,

- it should be possible to apply adhesive both on the top and on the side surfaces of the items,

- adhesive will be applied by spraying,

\footnotetext{
*Corresponding author: aleksandra.fierek@put.poznan.pl

Reviewers: Maciej Bodnicki, Vladimir Dekýš
} 
- the spray head manufactured by Spraying System Co. will be used, composed of 10535 $1 / 4 \mathrm{~J}$ body and SUE45A nozzle,

- simplicity of the mechanical part of the machine and the control system design are aimed at,

- it must be possible to clean the machine with water,

- there should be a measure to drain off excess amount of adhesive from the work area.

Two concepts of the machine design were proposed based on the foregoing requirements. The difference between them lies in the type of the feeder, namely belt conveyor and rotary table respectively. The above-mentioned spray unit is fitted in a specially designed mechanical system placed over the machine work area. This mechanical system governs the movement of the spray unit, ensuring that adhesive is applied where required. The two options are presented below - belt conveyor option in Fig. 1 and rotary table option in Fig. 2.

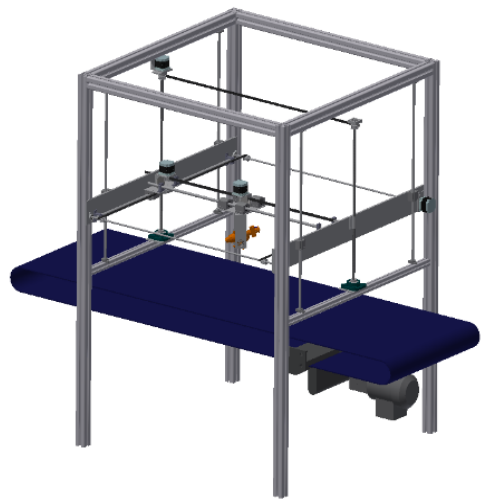

Fig. 1. Model of the belt conveyor option

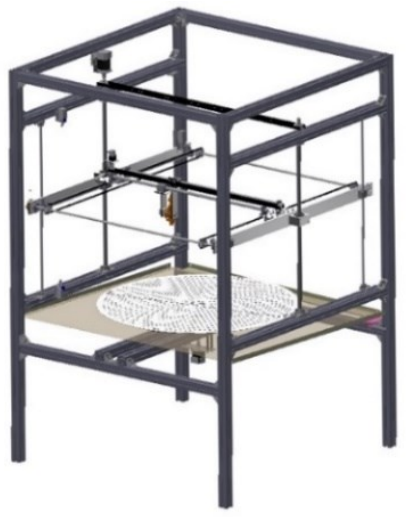

Fig. 2. Model of the rotary table option

Taking into account all the pros and cons the rotary table option was chosen for the further part of the engineering process. The advantages of this option include a smaller number of drives needed to control the movements, smaller dimensions of the machine and easier draining of excess adhesive from the work surface. The belt conveyor in turn offers the possibility of automatic feeding and positioning of the items in the machine work area which is not available in the rotary table option. However, automatic feeding option is not precluded and can be added to the production machine, if required.

\section{Structural design of the machine according to the chosen concept}

It was established that at least five axes of motion are required for the tasks to be performed by the machine. Therefore, five functional modules have been identified, namely: rotary table, spray unit tilt module and modules governing the movement of the spray unit along the $x, y$ and $z$ axes. The movements are generated by stepper motors, one per axis. This arrangement will facilitate control of the production machine. The remaining components making up the structural part of the system include the frame, the guards and the adhesive draining system.

The structural design stage of the engineering process included performance calculations for the respective modules, taking into account their interactions. These calculations enabled specifying appropriate structural components and operating devices (actuators). The calculations covered, inter alia: structural strength of the components, specification of the 
screw-nut mechanism, drives and the guideway system and durability of bearings was also predicted.

\subsection{The rotary table design and description of the related engineering process}

Fig. 3 displays a model of the rotary table module naming the main parts.

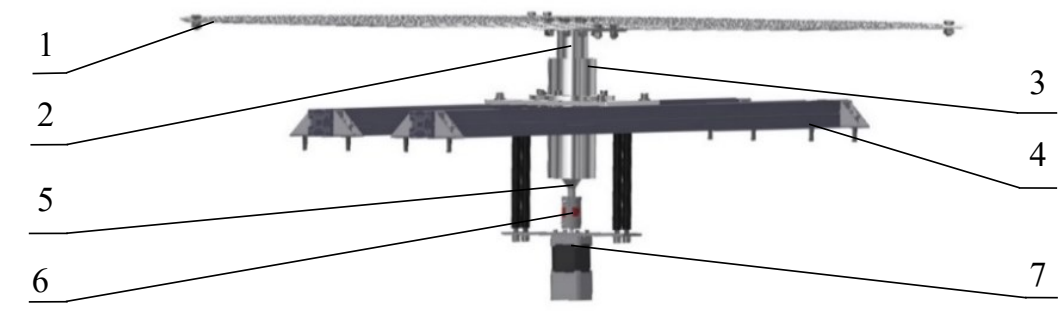

Fig. 3. Overview of the rotary table module and its components: 1 - perforated plate, 2 - connecting bush, 3 - bearings bush, 4 - frame, 5 - drive shaft, 6 - coupling, 7 - stepper motor

In the first step the diameter of the perforated plate $d_{p}$ was determined so as to provide the required machine work area. It was taken as equal to the diagonal of the $600 \times 800 \mathrm{~mm}$ rectangle. Next the required torque to be provided by the stepper motor was calculated. The calculation included both the resistance due to friction in the bearings and the mass moment of inertia depending on the size of the perforated plate and the items placed thereon. The values of the moment of inertia play a role during system acceleration and braking. The input data were the plate mass $m_{p}$ and the maximum permitted load applied on the plate $m_{o}$ distributed uniformly over the work area rectangle. The moments of inertia of the plate $I_{p}$ and of an item placed thereon $I_{o}$ were obtained using the known relationships. The moment of friction $M_{T}$ was calculated for the assumed force $Q$ created by the weight of the components of the mechanism and acting on a pre-defined average diameter. The coefficient of rolling friction was taken at $\mu=0.002$. The results obtained in this way were used as the basis for stepper motor selection. Next the drive shaft diameter $d_{w}$ was determined as the minimum value that satisfies the torsional strength and torsional flexibility criteria. The permitted value of the angle of twist per unit length of the shaft was taken at $\varphi_{\max }=0.004[\mathrm{rad} / \mathrm{m}]$. These values were used to design a shaft of an adequate diameter and properties and then a coupling was selected to connect the driving shaft with the stepper motor output shaft. The driving shaft is connected with the perforated plate by a keyed joint. The allowable contact stress of the keyed joint was determined. Taking into account the transmitted loads two 2RS type sealed angular contact bearings were specified to support the driving shaft. The minimum service life was predicted, expressed in operating hours. 


\subsection{The spray head tilt module design and description of the related engineering process}

Fig. 4 presents the model of the spray head tilt module naming the main parts.

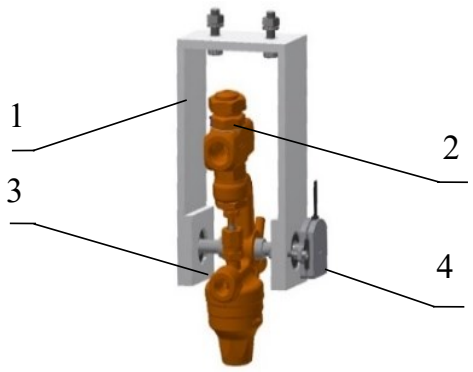

Fig. 4. Spray head tilt module: 1 - spray head holding bracket, 2 - spray head, 3 - shaft, 4 - stepper motor

For the module in question the torque of the stepper motor was determined on the basis of the friction resistance in the shaft bearings. 2RS type sealed bearings were chosen to support the spray head. In order to calculate the friction torque generated in the system it was necessary to know the total weight of the spray head and of the moving parts, designated $Q_{d}$. Moreover, friction mean diameter was determined for the selected bearings. The coefficient of rolling friction was taken at $\mu=0.002$. Given the above inputs the friction torque was calculated, which was next used for selecting an appropriate stepper motor. Other factors taken into account were the weight of the motor and simple installation. Thus a pancake stepper motor was chosen, as shown in Fig. 4. As the final step the durability of bearings expressed in operating hours was calculated.

\subsection{The spraying system $x$-axis module design and description of the related engineering process.}

Fig. 5 presents the model of the module in question, giving the names of its main parts.

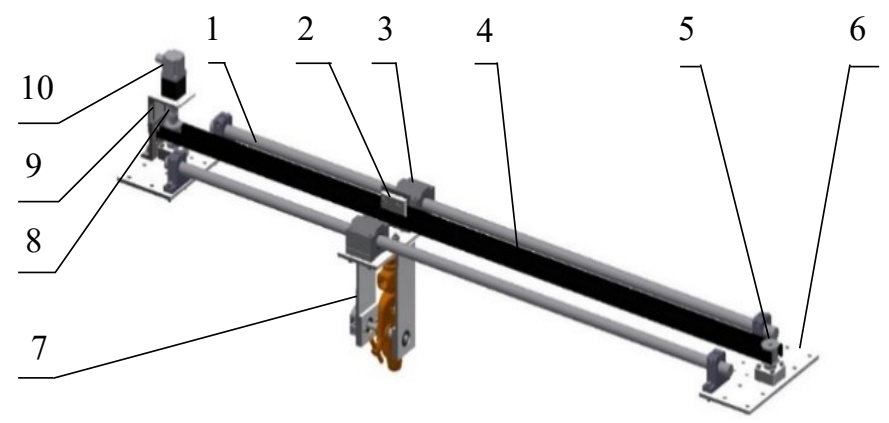

Fig. 5. The spraying unit $x$-axis module composed of: 1 - linear shaft, 2 - timing belt, 3 - rail carriage, 4 - timing belt, 5 - timing pulley, 6 - connecting side rail, 7 - spray head module, 8 - coupling, 9 - motor holder, 10 - stepper motor

The mechanism to convert rotary motion of the stepper motor into linear motion is made up of linear guideway system coupled with a belt transmission system.

The spray head tilt module is mounted on the rail carriages. The maximum force acting on the guideway system, $Q_{x}$, was determined and uniform distribution between the two guideways was assumed. The bending forces are decisive for this system. Therefore, bending 
criterion was used in the calculations to determine the minimum required linear shaft diameter. The schematic of loading of a single guideway is displayed in Fig. 6 below.

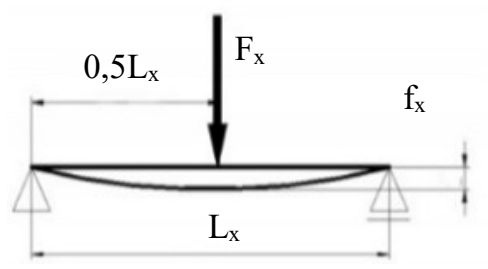

Fig. 6. Load diagram of the analysed linear shaft where $F_{x}$ - force acting on one guideway

The minimum required linear shaft diameter $d_{x}$ was determined by verifying the strength design criteria for bending (1) and the maximum deflection (2) taking $f=0.00025 \cdot \mathrm{L}_{\mathrm{x}}$ as the maximum allowed value. The following relationships were used for these checks [6]:

$$
\begin{gathered}
\sigma_{g}=\frac{M_{g x}}{W_{x}} \leq k_{g}, \\
f_{x}=\frac{F_{x} \cdot L_{x}^{3}}{48 E I} \leq f_{\text {allowed }} .
\end{gathered}
$$

Two different values of the minimum diameter $d_{w}$ were obtained from the rearranged equations of the strength design criterion for bending (1) and the maximum deflection criterion (2). The greater of these two was the value obtained with the absolute maximum deflection criterion. On this basis appropriate linear shafts and rail carriages were chosen from the products available in the market taking a diameter greater than the value determined as above. Moreover, the equations given in the product catalogues were used to calculate the nominal durability of the linear bearings in the chosen rail carriages.

The mechanism responsible for the transmission of power and for conversion of rotary motion to linear motion is the specially designed belt drive system. The belt drive system comprises a timing pulley and a mating timing belt. The belt length was calculated. The friction torque was determined for the adopted structural parameters of the belt drive, rail carriages and the acting forces. The result was increased by application of factors representing the efficiencies of the belt drive and shaft bearings of $\eta_{p}=0.96$ and $\eta_{t}=0.99$ respectively. On this basis the stepper motor was selected with appropriately higher available torque. For the selected motor the minimum and maximum rotational speeds $n$ [rpm] were figured out from the charts given in the product sheet. Given the belt drive parameters and the rotational speed of the motor, the minimum and maximum achievable linear speeds were obtained. 


\subsection{The spraying system $y$-axis module design and description of the related engineering process}

Fig. 7 presents the model of the module in question, giving the names of its main parts.

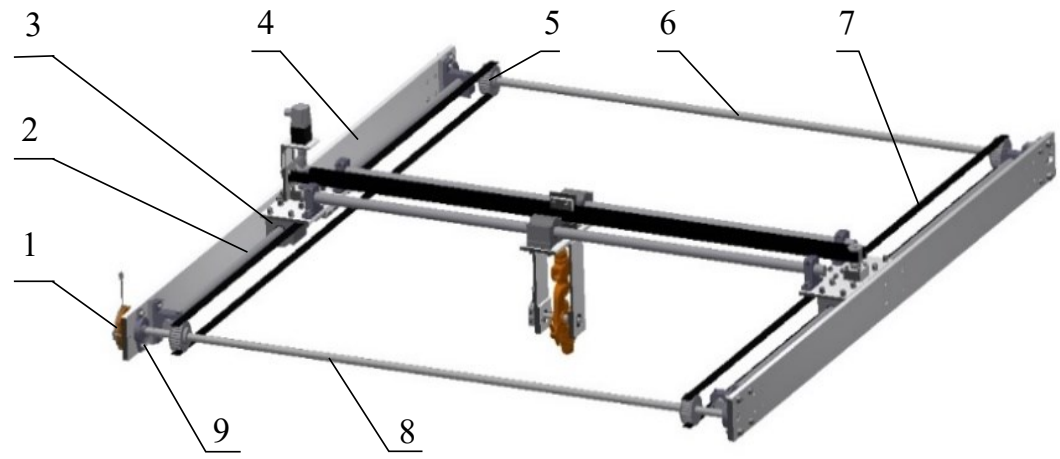

Fig. 7. The spraying system $y$-axis module composed of: 1 - stepper motor, 2 - linear shaft, 3 - rail carriage, 4 - connecting side rail, 5 - timing pulley, 6 - idler shaft, 7 - timing belt, 8 - drive shaft, 9 - bearing unit

The strength calculations for the guideways are in this case more complicated as compared to the $x$-axis module. The force diagram is displayed in Fig. 8 below.

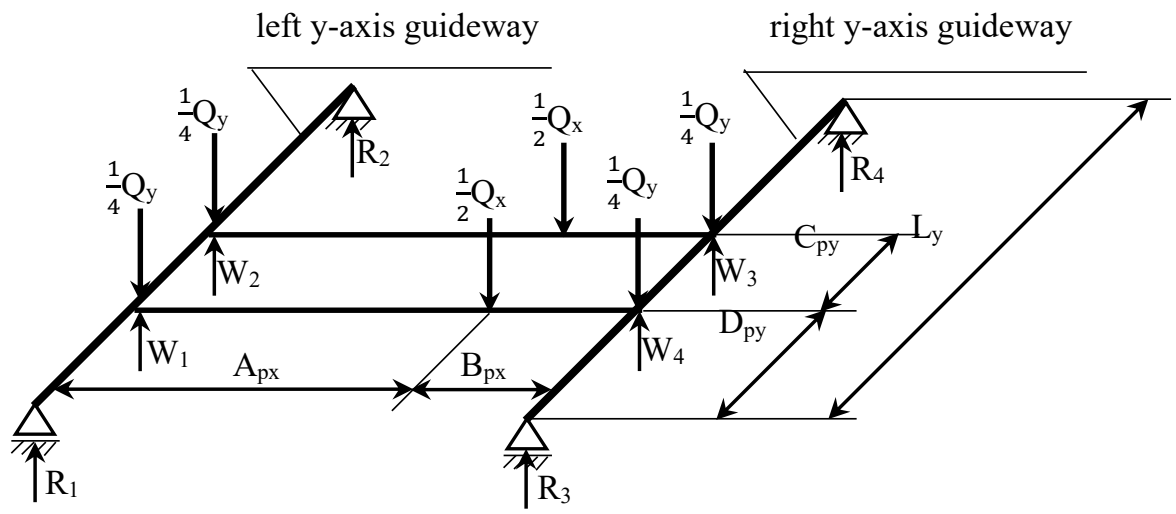

Fig. 8. The load diagram used for calculating the strengths of the $y$-axis guideways, where: $Q_{x}-$ force acting on the $y$-axis guideways along the $x$ axis; $Q_{y}$ - force acting on the $y$-axis guideways; $L_{y}$ - length of $y$-axis guideway; $A_{p x}, B_{p x}$-distances from the rail carriage centre; $C_{p y}$-distance between the centres of rail carriages; $D_{p y}$ - distance between the rail carriage centre and the support; $R_{I-4-\text { support reactions }}$ of the $y$-axis shafts; $\mathrm{W}_{1-4}-$ reactions at the rail carriage positions

The analysis was conducted for the situation with the $x$-axis module located as close as possible to one of the guideways (the module was replaced by the force $Q_{x}$ as displayed in Fig. 8) when:

- for the left-hand guideway the reactions generated by the $Q_{x}$ force components at points $W_{l}$ and $W_{2}$ assume the minimum values, yet there is a twisting moment acting on them created by force $Q_{x}$ acting with the lever $\operatorname{arm} A_{p x}$,

- for the right-hand guideway the reactions generated by the $Q_{x}$ force components at points $W_{3}$ and $W_{4}$ assume the highest value with the twisting moment at its minimum. 
The lengths of dimensions $L_{y}, A_{p x}$ and $B_{p x}$ result from the structural analysis and their values were calculated using a model created in the Inventor 2017 program. With the assumed uniform distribution of force $Q_{x}$ between the $x$-axis guideways the distribution of forces at points $W_{1}$ and $W_{2}$ will be the same as at points $W_{3}$ and $W_{4}$. After re-writing the following equilibrium equations of forces (3) and moments (4):

$$
\begin{gathered}
\sum F_{x}=W_{1}+W_{3}-0.5 Q_{x}=0, \\
\sum M_{W_{1}}=W_{3} \cdot\left(A_{p x}+B_{p x}\right)-0.5 Q_{x} \cdot A_{p x}=0,
\end{gathered}
$$

and fitting the input data we get the reactions at these points. According to the calculations for the system displayed in Fig. 8 the guideway on the right-hand side receives almost the whole load created by the masses travelling along the $x$-axis. The same distribution of forces on points $W_{l}$ and $W_{3}$ would be obtained with the masses placed at the midspan of the $x$-axis guideway.

The such a loading case the required strength was determined for the left- and right-hand guideways. For the left-hand guideway the reduced moment comprises bending moments created by the $0.25 \cdot Q_{y}$ forces acting on each of the two rail carriages, the resultants at points $W_{1}$ and $W_{2}$ and the twisting moment produced by force $Q_{x}$ for each of the two rail carriages. In order to obtain the bending moment it is necessary to determine the reactions at supports $R_{1}$ and $R_{2}$. With the assumed uniform distribution of forces $Q_{x}$ and $Q_{y}$, the system will be statically determinate. The following equilibrium equations of forces (5) and moments (6) on the left-hand guideway:

$$
\begin{gathered}
\sum F_{y}=R_{1}+R_{2}-W_{1}-W_{2}-0.25 \cdot Q_{y}-0.25 \cdot Q_{y}=0 \\
\sum M_{R_{1}}=W_{1} \cdot D_{p y}+0.25 Q_{y} \cdot D_{p y}+W_{2}\left(D_{p y}+C_{p y}\right)+0.25 \cdot Q_{y}\left(D_{p y}+C_{p y}\right)-R_{2} \cdot L_{y}=0
\end{gathered}
$$

were used to determine the reactions at supports $R_{1}$ and $R_{2}$, based on the assumption that the forces at the points $W_{l}$ and $W_{2}$ are always the same. The following (7) and (8) equations were used to calculate the bending moment for the left-hand guideway produced by the forces carried by the rail carriages:

$$
\begin{gathered}
M_{\mathrm{gW}_{1}}=\mathrm{R}_{1} \cdot \mathrm{D}_{\mathrm{py}}, \\
\mathrm{M}_{\mathrm{gW}_{2}}=\mathrm{R}_{2} \cdot\left(\mathrm{L}_{\mathrm{y}}-\mathrm{C}_{\mathrm{py}}-\mathrm{D}_{\mathrm{py}}\right) .
\end{gathered}
$$

The value of bending moment was calculated for the distance $D_{p y}$ at which the bending moment adopts the highest value. Besides the bending moment the left-hand guideway will be additionally subjected to a twisting moment $M_{s y l}$ produced by force $Q_{x}$ acting with the lever $\operatorname{arm} A_{p x}$. Also the value of this moment was calculated. Given the bending and twisting moments the following equation was used to calculate the reduced moment $M_{y z r e d}$ acting on the left-hand guideway:

$$
M_{y l z r e d}=\sqrt{M_{\text {gymax }}^{2}+0.75 \cdot M_{s y}^{2}}
$$

Next the reduced moment was used to calculate the minimum diameter of the $y$-axis lefthand linear shaft $d_{y l}$ from the bending strength design criterion.

The same procedure was applied to the right-hand guideway, the only difference being the distance and the forces. In the equilibrium equations of forces (3) and moments (4) forces $W_{l}$ and $W_{2}$ are replaced by forces $W_{3}$ and $W_{4}$ and forces $R_{1}$ and $R_{2}$ are replaced with $R_{3}$ and $R_{4}$ respectively. For the twisting moment the change concerns the lever arm, namely $B_{p x}$. in 
place of $A_{p x}$. Finally, the minimum diameter of the right-hand linear shaft $d_{y p}$ was calculated for the system in consideration.

Besides the bending moments also the maximum allowable deflection of the guideway should be taken into account. For this reason the design criterion for the maximum allowable deflection was checked. In the $y$ axis there are two rail carriages travelling on the guideway. Fig. 9 displays the force diagram giving the designations of the respective distances used to determine the magnitudes of the maximum absolute deflection.

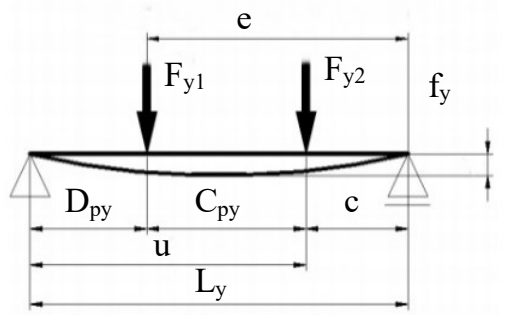

Fig. 9. Diagram used for determining the maximum absolute deflection, where: $F_{y 1}, F_{y 2}$ - forces exerted on the guideway by the respective rail carriages; $\mathrm{f}_{\mathrm{y}}$ - the maximum absolute deflection, $L_{y}$ - length of the $y$-axis guideway; $C_{p y}$ - distance between centres of rail carriages along $x$-axis; $D_{p y}, c$-distance from the rail carriage centre and the support; $e, u$ - distance from the rail carriage centre from the remote support

The magnitude of the maximum absolute deflection is calculated as follows [6]:

$$
f_{y}=\frac{F_{y 1} \cdot D_{p y}{ }^{2} \cdot e^{2}+F_{y 2} \cdot C_{p y}{ }^{2} \cdot u^{2}}{3 E I \cdot L_{y}} \leq f_{\text {allowed }}
$$

It was assumed that one of the two rail carriages is located at the point of the maximum bending moment along the guideway and that the force is distributed equally between the two rail carriages. Equation (10) was transformed to calculate the minimum required linear shaft diameter for the allowable maximum absolute deflection of $f_{\text {allowed }}=0.00025 \cdot L_{y}$. The obtained value was greater than the previous ones, calculated from the design failure criterion for bending. This being so, a considerably larger, commercially available linear shaft was specified. Also the rail carriages were specified, and their nominal service life in $[\mathrm{km}]$ was predicted.

Timing pulleys of appropriate diameter were specified and the required length of timing belts was calculated. These input data were used to determine the friction torque in the system. Assuming the efficiency of the support bearings of $\eta_{t}=0.99$ and the efficiency of power transmission of $\eta_{p}=0.96$ the stepper motor with appropriately greater torque was specified. The range of linear speed of travel along the $y$ axis was determined based on the catalogue data of the motor. The coupling and bearings were specified as the final step of this stage of engineering. 


\subsection{The spraying system z-axis module design and description of the related engineering process}

Fig. 10 presents the model of the $z$-axis module, giving the names of its main parts.

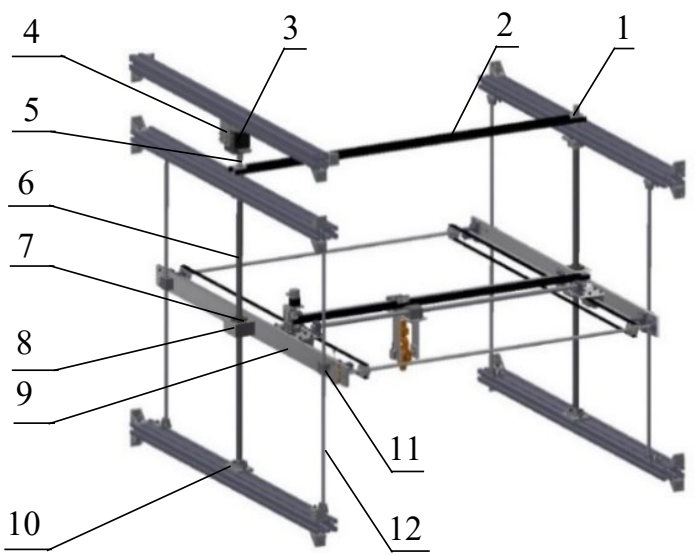

Fig. 10. The spraying system $z$-axis module composed of: 1 - timing pulley, 2 - timing belt, 3 - stepper motor, 4 - motor holder, 5 - coupling, 6 - trapezoidal screw, 7 - bronze nut, 8 - nut holder, 9 - connecting side rail, 10 - screw bearing block, 11 - rail carriage, 12- linear shaft

In the analysed system the rotary motion is converted to linear motion by screw-nut mechanisms. Timing belt drive system has been chosen for transmission of power from the stepper motor to both mechanisms to ensure that their motions are fully synchronised. The calculations included determining the required height of the nut and checking the thread strength. Moreover, considering the length of the trapezoidal screw defined by the machine design it was checked for the resistance to buckling. Timing pulleys were specified and the timing belt length was calculated. The stepper motor was selected on the basis of friction torque caused by friction between the steel screw and the bronze nut. The coefficient of sliding friction was taken at $\mu=0.18$. The maximum force acting on the system along $z$-axis, designated $Q_{z}$, was also determined. Given the pitch and the pitch diameter of the chosen trapezoidal screws it was possible to determine the flank angle, the apparent coefficient of friction and the apparent friction angle. The available input data were used to determine the friction torque, which due to occurrence of sliding friction is much greater than the friction torques occurring in the remaining axes. The stepper motor was selected with the rated torque appropriate to the efficiencies of the support bearings and of the power transmission system. Moreover, the range of linear speed of travel along the $y$ axis was calculated. Finally, the durability of bearings was predicted.

\subsection{Remaining parts of the mechanical part of the machine}

The strength of the machine support frame was checked with the guards in place. Perforated plate was chosen as the measure to drain off excess adhesive. Draining from the plate it will fall on a system comprising an inclined plate and gutters directing the liquid to the outlet funnel from which it can be, for example, returned to the tank. Protection from collision is provided by limit switches and reed switches are mounted on guards to ensure they are in closed position. The upper part of the machine is purposefully left open for ventilation. 


\section{Control system}

For automatic control of the machine operations an in-house developed control flow diagram was used, as presented in [7]. It includes a sequence of movements and operations to be performed by the machine to complete a given production process.

The control system design has been prepared for the already specified system components, including the stepper motors, limit switches and safety interlock switches. Appropriate stepper motor controllers were specified for each of the five designed stepper motors, on the basis of the required electric currents on the stepper motor windings. PLC was selected as the next step. For stepper motors control transistor outputs are required. This requirement results from the high output switching frequency. The switching frequency determines the achievable rotational speed and, as such, it should be appropriately high. To control all the designed stepper motors the controller has ten PNP transistor outputs, accompanied with 14 digital inputs. The transistor outputs are used to control the controllers of the stepper motors. The digital inputs receive signals from the sensors installed on the machine. In addition, an expansion module was specified for communication with HMI operator panel. An operator panel was designed to facilitate operation of the production machine.

An important advantage of stepper motors is their ability to recover energy for example during braking which must be utilised by appropriately designed power supply unit. For this reason transformer-based power supply was chosen. The power supply units were specified according to the input power of all the connected loads. For safety reasons the PLC and motor controllers are supplied by different power supplies.

\section{Final conclusions}

Sealed bearings, screens, stainless steel and aluminium framing members and minimised amount of electronic components make the machine sufficiently resistant to glue and enable cleaning with water. The simplicity of mechanical part of the machine is obtained by minimising the number of parts and by using off-the-shelf components, specified on the basis of the product catalogue data. This will facilitate building the prototype and future maintenance of the production machine. Availability of individual programs controlling the adhesive application process, dedicated to specific parts of the seating systems will lead to improved coating efficiency, minimising consumption of adhesive which is the objective of automation of the process under analysis. The HMI operator panel will, on the one hand, considerably facilitate operation of the production machine and, on the other, much more time will be needed to write the control program. The proposed structural design created through the above-described engineering process accompanied with the proposed control system should satisfy all the requirements relating to the adhesive application process and functioning of the machine. The assumptions and calculations made in the process of engineering, as well as correctness of the proposed model can be verified only with the machine prototype to be built for this purpose.

\section{References}

1. https://www.kiel-sitze.de/index.php/pl/Produkty (Access date: 23.08.2018)

2. https://simalfa.ch/pl/aplikacja-kleju/aplikacja-walcami/ (Access date: 23.08.2018)

3. http://www.lakiernictwo.net/dzial/142-aktualnosci-i-przeglad-rynku/artykuly/walce8211-natrysk-8211-polewanie,485/1 (Access date: 23.08.2018) 
4. Product catalogue of Spraying System Co., Sec. F - Air Atomizing Nozzles (http://www.spraying.pl/Assets/PL/ssco_cat70m-pl_f.pdf), pp. 1-6, 15, 18. (Access date: 23.08.2018)

5. Product catalogue of Spraying System Co, Sec. G - Automatic Spray Nozzles (http://www.spraying.pl/Assets/PL/ssco_cat70m-pl_g.pdf), pp. 1-3, 9. (Access date: 23.08.2018)

6. M. E. Niezgodziński, T. Niezgodziński, Strength equations, graphs and tables. Warsaw PWN (1973)

7. A. Fierek, Thesis: Mechatronic Unit for Application of Coats of Adhesive by spraying (2018) 